African Crop Science Journal by African Crop Science Society is licensed under a Creative Commons Attribution 3.0 Uganda License. Based on a work at www.ajol.info/ and www.bioline.org.br/cs DOI: http://dx.doi.org/10.4314/acsj.v26i1.3

\title{
LINEAR DISCRIMINANT ANALYSIS OF STRUCTURE WITHIN AFRICAN EGGPLANT 'SHUM'
}

\author{
G. SSEREMBA ${ }^{1,2}$, P. TONGOONA ${ }^{1}$, J.S.Y. ELEBLU ${ }^{1}$, E.Y. DANQUAH ${ }^{1}$ and E.B. KIZITO ${ }^{2}$ \\ ${ }^{1}$ West Africa Centre for Crop Improvement, University of Ghana, PMB 30, Accra, Ghana \\ ${ }^{2}$ Department of Agricultural and Biological Sciences, Faculty of Science and Technology, \\ Uganda Christian University, P. O. Box 4, Mukono, Uganda \\ Corresponding authors: ptongoona@wacci.edu.gh, lkizito08@gmail.com
}

(Received 10 August, 2017; accepted 2 February, 2018)

\begin{abstract}
African eggplant (Solanum aethiopicum) lags behind in terms of research attention; leading to, among other gaps, scantiness of information on intra-group genetic diversity. Hierarchical clustering was applied to reveal structure in a pioneer 20-entry set of S. aethiopicum Shum group accessions at Africa Solanaceae Research Network secretariat in Uganda, using 61 morpho-agronomic variables collected from a complete randomised design (CRD) with 12 plants per accession in screen-house. A MANOVA preceded linear discriminant analysis, to model each of 61 variables, as predicted by clusters and experiment to filter out non-significant traits. Four distinct clusters emerged, with a cophenetic relation coefficient of $0.87(\mathrm{P}<0.01)$. Canonical variates that best predicted the observed clusters include petiole length, sepal length (or seed color), fruit calyx length, seeds per fruit, leaf fresh weight (or leaves per plant), fruit fresh yield, seedling vigour, fruits per plant, harvest index and plant growth habit. Results suggest prospects for variety discrimination at various stages; seedling, vegetative and reproductive. The observed diversity will boost chances of effective selection for desired traits; while the canonical discriminant traits are potential morphological markers, within S. aethiopicum 'Shum' for a low-cost germplasm characterisation approach.
\end{abstract}

Key Words: Hierarchical clustering, morphological markers, Solanum aethiopicum

\section{RÉSUMÉ}

L'aubergine Africaine (Solanum aethiopicum) demeure en arrière en termes de travaux de recherches ; conduisant à, entre autres lacunes, manque d'information sur la diversité génétique intra-groupe. La classification hiérarchique était utilisée pour révéler la structure dans une série de 20 accessions de groupe Shum de S. aethiopicum au secrétariat du Réseau Africain de Recherches sur les Solanaceae utilisant 61 variables morpho-agronomiques collectées d'un design complet aléatoire (CRD) avec 12 plantes par accession sous la serre. Une MANOVA a précédé l'analyse discriminante linéaire, pour modéliser chacune des 61 variables, comme prédit par les classes et l'expérimentation pour filtrer les traits non-significatifs. Quatre différentes classes ont été identifiées, avec un coefficient de relation cophénétique de $0,87(\mathrm{P}<0,01)$. Les variables canoniques qui ont mieux prédit les classes observées comprenaient la longueur du pétiole, la longueur du sépale (ou la couleur des graines), la longueur du calice du fruit, le nombre de graines par fruit, le poids de feuilles fraîches (ou feuilles par plante), le poids du fruit non sec, la vigueur des plantules, le nombre de fruits par plante, l'indice de récolte et l'habitude de croissance du plant. Les résultats ont suggéré une discrimination de la variété à divers stades, semis, végétatif et reproductif. La diversité observée va augmenter les chances pour une sélection effective des traits désirés ; alors que les traits 
discriminants canoniques sont les marqueurs morphologiques, parmi le S. aethiopicum de type 'Shum' pour une approche de caractérisation à moindre coût du germplasm.

Mots Clés : Classification hiérarchique, marqueurs morphologiques, Solanum aethiopicum

\section{INTRODUCTION}

African eggplant (Solanum aethiopicum) is the third most important solanaceous crop species after tomato and potato, but little is known on the species' germplasm diversity (KietbowiczMatuk et al., 2014; Cernansky, 2015; Gramazio et al., 2016). Solanum aethiopicum consists of four recognised morphological groups (Aculeatum, Kumba, Gilo and Shum) each cultivated for a particular plant part and different purposes (Plazas et al., 2014; World Vegetable Center, 2017).

The Shum is a nutrient-rich leafy vegetable; a source of food and income in Uganda (Cernansky, 2015; Pincus, 2015) and other sub-Saharan Africa countries like Cameroon, Nigeria, Burkina-Faso and Côte d'Ivoire (Kouassi et al., 2014; Cernansky, 2015). Other groups such as the Gilo are also commercially produced in Latin America, Asia and across Africa (Plazas et al., 2014).

The crop's cultivation is dominated by smallholder farmers, who constitute the highest proportion of the sub-Saharan Africa populations (Abukutsa-Onyango, 2014; Von Grebmer et al., 2015). Farmers, however, experience low yields and low leaf quality, as a result of a number of constraints such as low soil fertility, drought stress, lack of quality seed, pests, diseases and postharvest deterioration (Abukutsa-Onyango, 2014; Pincus, 2015; Bisamaza and Banadda, 2017). Breeding for improved varieties to address the constraints is deemed the best strategy as it offers a lasting solution (Abukutsa-Onyango, 2014; Cernansky, 2015). However, the existence of within-group variability among the 'Shum' had not been investigated.

Lumped up accessions from the different cultivar groups are reported to exhibit diversity in morphological traits (Plazas et al., 2014).
Conspicuously, the Shum were notably insufficiently represented when compared with the Gilo, for example (Adeniji et al., 2012; Plazas et al., 2014). The lumping up and limited representation for the Shum could have masked the exposure of within-group structure (Plazas et al., 2014). Because Shum is leafy type, but reproductively propagated crop, adequate inclusion of leaf traits at seedling and harvestmaturity (vegetative) stages; as well as reproductive attributes ought to be ensured in a comprehensive genetic diversity analysis based on morphology (World Vegetable Center, 2017).

Statistical approaches like cluster analysis and linear discriminant analysis (LDA) are popular and adequate for the genetic diversity analysis (Asher et al., 2017). Cluster analysis in graphic user interface softwares like R, is effective for large data sets for both quantitative and qualitative variables (Hornik and Böhm, 2017; Murtagh, 2017). The clustering can be based on a number of alogarithms such as complete linkage, Ward's method and the Unweighted Pair Group Method with Arithmetic mean (UPGMA) method (Saraçli et al., 2013).

The UPGMA is also referred to as the "average" method and it was applied in this study due to its popularity and acceptability. The strength of clustering can be evaluated by way of coefficients, such as agglomerative coefficient and cophenetic correlation coefficient (CPCC, Saracli et al. (2013). The CPCC is a common and reliable measure of dissimilarity among formed clusters (Saraçli et al., 2013; Silva and Dias, 2013; Murtagh, 2017; Nikoliæ et al., 2017).

In order to identify and quantify traits' contribution for best prediction of observed clusters in the dendrogram, LDA (also called canonical discriminant analysis) is a suited 
approach (Harding and Payne, 2012). Discriminant analysis refers to a linear combination of data variates (original variables) as loadings, which maximises between-cluster variance and minimise within-cluster variance (Jombart and Collins, 2015). It relies on allocation of groups (observed or assigned) as dependent variables to be predicted by data (variates).

The LDA has been applied in medicine, animal (Arandas et al., 2017) and plant research. In plants, LDA has been applied in various studies such as taxonomic and germplasm characterisation (Herklotz et al., 2017), phenotypic changes evaluation in plant species over time (Alberti et al., 2017) and crop diseases detection on remote sensing generated data (Bajwa et al., 2017).

In the Shum group of S. aethiopicum, LDA was applied in this study to investigate the morphological diversity of available germplasm, in order to ascertain its suitability for conservation and usefulness in genetic improvement of farmes' cultivars for desired traits through breeding.

The objective of this study was, therefore, to investigate the existence and drivers of structure within $S$. aethiopicum Shum group. We hypothesized that there is considerable variation within $S$. aethiopicum Shum group, as a starting point towards selection for superior varieties and affor germplasm characterisation within the subspecies.

\section{MATERIALS AND METHODS}

Germplasm and research site. A pioneer set of 20 accessions of S. aethiopicum Shum were obtained from the secretariat of Africa Solanaceae Research Network (Afri-SOL) at the Department of Agricultural and Biological Sciences (DABS), in Uganda Christian University (UCU); Mukono Municipality, Uganda. Afri-SOL, affiliated to Sol Genomics Network, is a network of scientists and other stakeholders with interest in solanaceous species in Africa (www.afri-sol.org/). The study was carried out in screen house at DABS-UCU between April 2016 and March 2017. The study accessions are described in Table 1.

Experimental design. The study was carried out using pots in the screen house in 2016, and October 2016 - March 2017, respectively. The potting substrate was composed of thoroughly mixed topsoil (clay loams) and cowdung manure in a ratio of 5topsoil:2 manure. A fortnightly schedule for insecticide (profenofos and cypermethrin at $2 \mathrm{ml} \mathrm{L}^{-1}$ of water), fungicide (metalaxyl and mancozeb at $2 \mathrm{~g} \mathrm{~L}^{-1}$ of water) and fertiliser (C.A.N at $4 \mathrm{~g}$ pot $^{-1}$ ) were administered.

Watering was carefully carried out using tap water delivered through a hosepipe on a daily basis. A completely randomised design was used in which 24 plants (12 for data collection at seedling/vegetative stages, and remaining 12 for reproductive/fruiting stage) per accession were evaluated. Each pot was

TABLE 1. List of S. aethiopicum Shum accessions used for the screen house study

\begin{tabular}{lll}
\hline Serial no. & Accession & Pedigree \\
\hline 1 & $168 \mathrm{G}$ & SAS168/G/2015 \\
2 & $183 \mathrm{G}$ & SAS183/G/2015 \\
3 & 163 & SAS163/2015 \\
4 & $163 \mathrm{P}$ & SAS163/P/2015 \\
5 & $157 \mathrm{P}$ & SAS157/P/2015 \\
6 & 160 & SAS160/2015 \\
7 & $163 \mathrm{G}$ & SAS163/G/2015 \\
8 & $183 \mathrm{P}$ & SAS183/P/2015 \\
9 & 108 & SAS108/2015 \\
10 & $157 \mathrm{G}$ & SAS157/G/2015 \\
11 & 148 & SAS148/2015 \\
12 & 145 & SAS145/2015 \\
13 & $168 \mathrm{P}$ & SAS168/P/2015 \\
14 & $184 \mathrm{G}$ & SAS184/G/2015 \\
15 & 137 & SAS137/2015 \\
16 & $184 \mathrm{P}$ & SAS184/P/2015 \\
17 & 141 & SAS141/2015 \\
18 & $108 \mathrm{P}$ & SAS108/P/2015 \\
19 & $185 \mathrm{G}$ & SAS185/G/2017 \\
20 & $185 \mathrm{P}$ & SAS185/P/2015 \\
\hline
\end{tabular}


planted with two seedlings at the four-leaf stage (four weeks after sowing in a nursery); followed by thinning to one plant per pot. The individual plant in a pot was the observational unit.

\section{Data collection and analysis}

Hierarchical clustering. Data were collected on a total of 61 morpho-agronomic traits, at different stages of crop growth, namely cotyledonous and seedling, vegetative and reproductive/ fruiting. This number of variables excludes those that did not significantly differ for at least two accessions $(\mathrm{P}<0.05)$. The vegetative stage, at 4 weeks after transplanting (WAT), is the harvest stage (since $S$. aethiopicum Shum is a leafy vegetable), at which leaf, shoot and root weights were taken. A summary of the scale or units of measurement for the different traits is included in Table 2, and most of these traits have been described earlier by Plazas et al. (2014), Adeniji et al. (2012, 2013) and Kubie (2013). The variables were summarised in Excel to obtain means. A table of means per trait for each accession was then imported into $\mathrm{R}$ statistical software for UPGMA reordered hierarchical cluster analysis. A mantel test (cophenetic correlation coefficient, CPCC) for significance of clustering was also performed.

Discriminant analysis of clusters. After clustering, the raw data file (in Excel) was updated with a column named 'cluster', to assign a group number to each accession (member) as determined from dendrogram. A multivariate analysis of variance (MANOVA) was then carried out (for the 61 variables) to identify traits that significantly $(\mathrm{P}<0.01)$ contributed to observed clusters in the dendrogram. The following two-way MANOVA model was analysed in GenStat $12^{\text {th }}$ Edition (VSN International Ltd):

$$
y_{i j}=\mu+C_{i}+R_{j}+\varepsilon_{i j}
$$

Where: $y_{i j}$ is the observed trait measurement for a group of accessions in the $i^{\text {th }}$ cluster (C) and $j^{\text {th }}$ experiment $(\mathrm{R}) ; \mu$ and $\varepsilon_{i j}$ refer to overall cluster mean for a trait and random error, respectively.

The traits (variables) which did not significantly differ for at least two clusters $(\alpha$ $=1 \%$ ) were excluded from discriminant analysis (DA). The DA in GenStat generates c-1 number of discriminant functions (DFs, where $c=$ number of clusters), correlations between data variates and DFs, discriminant scores for cluster means and Mahalanobis' $\left(\mathrm{D}^{2}\right)$ inter-cluster distances. Finally, a Pearson's correlation between canonical variates was carried out to identify variate (morphological marker) alternatives for strongly correlated traits.

\section{RESULTS}

Hierarchical clustering. Observed clustering in the dendrogram (Fig. 1) showed four distinct clusters, with a CPCC of $0.87(\mathrm{P}<0.05)$. Cluster 3 was the richest; followed by cluster 2. Cluster 4 and cluster1 had only one and two members, respectively (Table 3 ).

The mean performance of accessions also showed differences for different variables. Accessions 160 and 145, which constituted cluster 4 had higher petiole length (PEL), sepal length (SEL), fruit length (FRL), fruit breadth (FRB), fruit calyx length (FCL), fruit cross section diameter (FCD), fruit fresh weight (FFW) and seeds per fruit (SPF) than the rest of accessions. Accession 185P Cluster 1 uniquely had the highest number of fruits per plant (FPP) and fruit fresh yield (FFY).

Discriminant analysis of clusters. The MANOVA eliminated 11 variables on the basis of non-significance in cluster discrimination (Table 4). The eliminated variables include FPL, LBW, LL, LMC, LSL, LVP, PC, PP, SBD, SBF, and SOS. Linear discriminant analysis (LDA) on the remaining 50 variables (now factor variates) produced 3 discriminant functions 
TABLE 2. Summary of 61 variables recorded

\begin{tabular}{|c|c|c|c|c|c|}
\hline Variable & Unit/scale & Variable & Unit/scale & Variable & Unit/scale \\
\hline Days to emergence (DG) & Days & Shoot flesh biomass (SBF) & $\mathrm{g}$ & Flowers per inflorescence (FLI) & Counts \\
\hline Cotyledonous leaf length (CLBL) & $\mathrm{mm}$ & Shoot dry biomass (SBD) & $\mathrm{g}$ & Stamen length $(\mathrm{mm})(\mathrm{N}=5)(\mathrm{STL})$ & $\mathrm{mm}$ \\
\hline Cotyledonous leaf width (CLBW) & $\mathrm{mm}$ & Harvest fresh index (HIF) & Ratio & Petal length $(\mathrm{mm})(\mathrm{N}=5)(\mathrm{PEL})$ & $\mathrm{mm}$ \\
\hline Visual seedling vigour (VSV) & Scale (1-5) & Harvest dry index (HID) & Ratio & Sepal length $(\mathrm{N}=5)(\mathrm{SEL})$ & $\mathrm{mm}$ \\
\hline Seedling leaf length (SLBL) & $\mathrm{mm}$ & Plant growth habit (PGH) & Scale (1-9) & Relative style length (mm) (RSL) & $\mathrm{mm}$ \\
\hline Seedling leaf width (SLBW & $\mathrm{mm}$ & Spines on stem (SOS) & Scale (1-9) & Pollen production (POL) & Scale $(0-7)$ \\
\hline Seedling fresh weight (SDFW) & $\mathrm{mg}$ & Stem pubescence (SPU) & Scale (1-4) & Fruit length (mm) (FRL) & $\mathrm{mm}$ \\
\hline Seedling dry weight (SDDW) & $\mathrm{mg}$ & Stem colour (SC) & Scale (1-3) & Fruit breadth $(\mathrm{mm})(\mathrm{FRB})$ & $\mathrm{mm}$ \\
\hline Leaf blade length (LBL) & $\mathrm{cm}$ & Petiole colour (PC) & Scale (1-3) & Fruit pedicel length (mm) (FPL) & $\mathrm{mm}$ \\
\hline Leaf blade width (LBW) & $\mathrm{cm}$ & Petiole prickles (PP) & Scale (1-9) & Fruit pedicel thickness (mm) (FPT) & $\mathrm{mm}$ \\
\hline Leaf area & $\mathrm{cm}^{2}$ & Leaf blade lobbing (LL) & Scale (1-9) & Fruit color at physiological ripeness (FCP) & Scale (1-9) \\
\hline Leaves per plant (LPP) & Counts & Leaf blade tip angle (LTA) & Scale (1-9) & Fruit position (FRP) & Scale (1-9) \\
\hline Plant branching $(\mathrm{PB})$ & Counts & Leaf blade color (LBC) & Scale (1-3) & Fruit calyx length $(\mathrm{N}=10)(\mathrm{FCL})$ & $\mathrm{mm}$ \\
\hline Plant height (PH) & $\mathrm{cm}$ & Leaf vein pigmentation (LVP) & Scale (1-3) & Fruit cross section diameter $(\mathrm{N}=10)(\mathrm{FCD})$ & $\mathrm{mm}$ \\
\hline Plant width (PW) & $\mathrm{cm}$ & Leaf mid rib color (LMC) & Scale (1-3) & Locules per fruit $(\mathrm{N}=10)(\mathrm{LPF})$ & Counts \\
\hline Leaf relative water content (LRWC) & $\%$ & Leaf spines on upper surface (LSU) & Scale (1-9) & Fruit fresh weight $(\mathrm{N}=10)(\mathrm{FFW})$ & $\mathrm{g} /$ fruit \\
\hline Leaf fresh weight (LFW) & $\mathrm{mg}$ & Leaf spines on lower surface (LSL) & Scale (1-9) & Fruits per inflorescence $(\mathrm{N}=5)(\mathrm{FPI})$ & Counts \\
\hline Leaf dry weight (LDW) & mg & Leaf pubescence on upper surface (LHU) & Scale (1-9) & Fruits per plant (FPP) & Counts \\
\hline Leaf fresh yield (LFY) & g & Leaf pubescence on lower surface (LHL) & Scale (1-9) & Fruit fresh yield per plant (FFY) & g plant ${ }^{-1}$ \\
\hline \multirow[t]{2}{*}{ Leaf dry yield (LDY) } & $\mathrm{g}$ & Date to first flower appearance (FLW) & Days & Seed color (SEC) & Scale (1-9) \\
\hline & & & & Seeds per fruit (SPF) & Counts \\
\hline
\end{tabular}




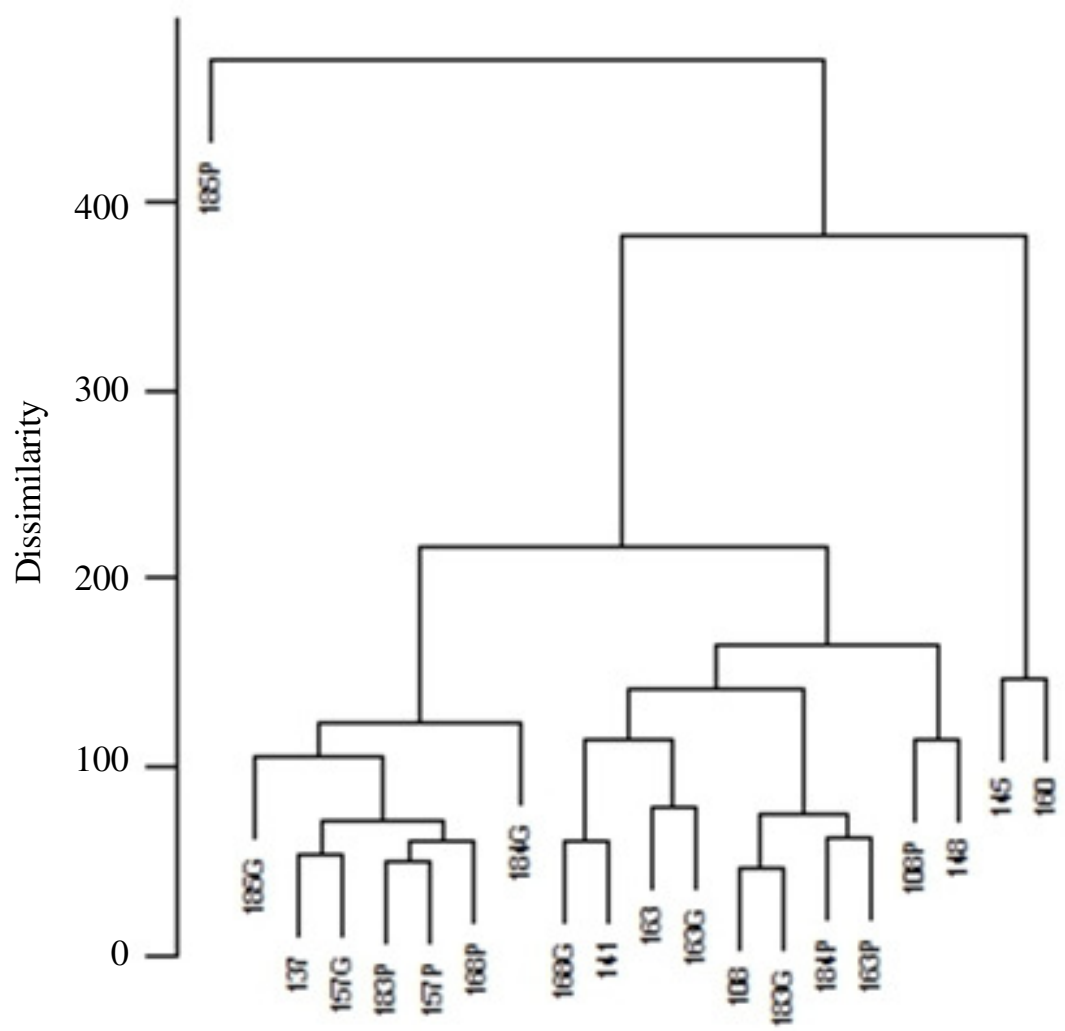

Figure 1. Reordered hierarchical clustering of study accessions using UPGMA method.

(DFs) consisting of vector loadings or DF scores for each variate. The canonical Pearson's product-moment correlation coefficients for DF 1, DF 2 and DF 3 were $0.9999,0.9973$ and 0.9727 , respectively. A biplot of the first two DF scores showed a clear separation among 4 clusters. The first DF separated Cluster 4 from the rest; while the second DF distinguished Cluster 1, Cluster 2 and cluster 3 (Fig. 2). Further, discriminant scores for cluster means under DF 1, DF 2 and DF 3 were highest for Cluster 1 and 4, Cluster 1; followed by Cluster 3 and Cluster 1 ; which was in turn followed by Cluster 2 . The $\mathrm{D}^{2}$ (Mahalanobis' inter-cluster distances) scores were highest between Cluster 4 and any of the remaining clusters followed by Cluster 1 and Cluster $3\left(D^{2}=2694\right)$, and Cluster 1 and Cluster $2\left(D^{2}=1352\right)$.
Cluster 2 and Cluster 3 had the lowest score for inter-cluster distance at 438 (Table 5). Correlations between 50 data variates and 3 DFs produced SEC (-0.05), PEL (-0.03), SEL $(-0.02)$, SPF (-0.02) and FCL $(-0.02)$ as the canonical variates in the first DF. In the second DF, LFY and FFY had the highest scores, both at 0.06 and -0.06 , respectively; followed by VSV and FPP both at 0.04 and -0.04 , respectively. In the last DF, the following variates had high scores in the order of HID (0.13), followed by HIF (0.11), PGH (0.08), and LPP and LFY both at 0.07. Strong correlations between some variates were also observed. For instance, HIF and HID ( $\mathrm{r}=$ $0.52)$, SEC and SEL $(r=0.62)$, and LFY and LPP $(r=0.76)$ are correlated traits. 
Linear discriminant analysis of structure within African eggplant

TABLE 3. Cluster membership of study accessions

\begin{tabular}{lll}
\hline Serial no. & Accession & Cluster \\
\hline 1 & $168 \mathrm{G}$ & 3 \\
2 & $183 \mathrm{G}$ & 3 \\
3 & 163 & 3 \\
4 & $163 \mathrm{P}$ & 3 \\
5 & $157 \mathrm{P}$ & 2 \\
6 & 160 & 4 \\
7 & $163 \mathrm{G}$ & 3 \\
8 & $183 \mathrm{P}$ & 2 \\
9 & 108 & 3 \\
10 & $157 \mathrm{G}$ & 2 \\
11 & 148 & 3 \\
12 & 145 & 4 \\
13 & $168 \mathrm{P}$ & 2 \\
14 & $184 \mathrm{G}$ & 2 \\
15 & 137 & 2 \\
16 & $184 \mathrm{P}$ & 3 \\
17 & 141 & 3 \\
18 & $108 \mathrm{P}$ & 3 \\
19 & $185 \mathrm{G}$ & 2 \\
20 & $185 \mathrm{P}$ & 1 \\
\hline
\end{tabular}

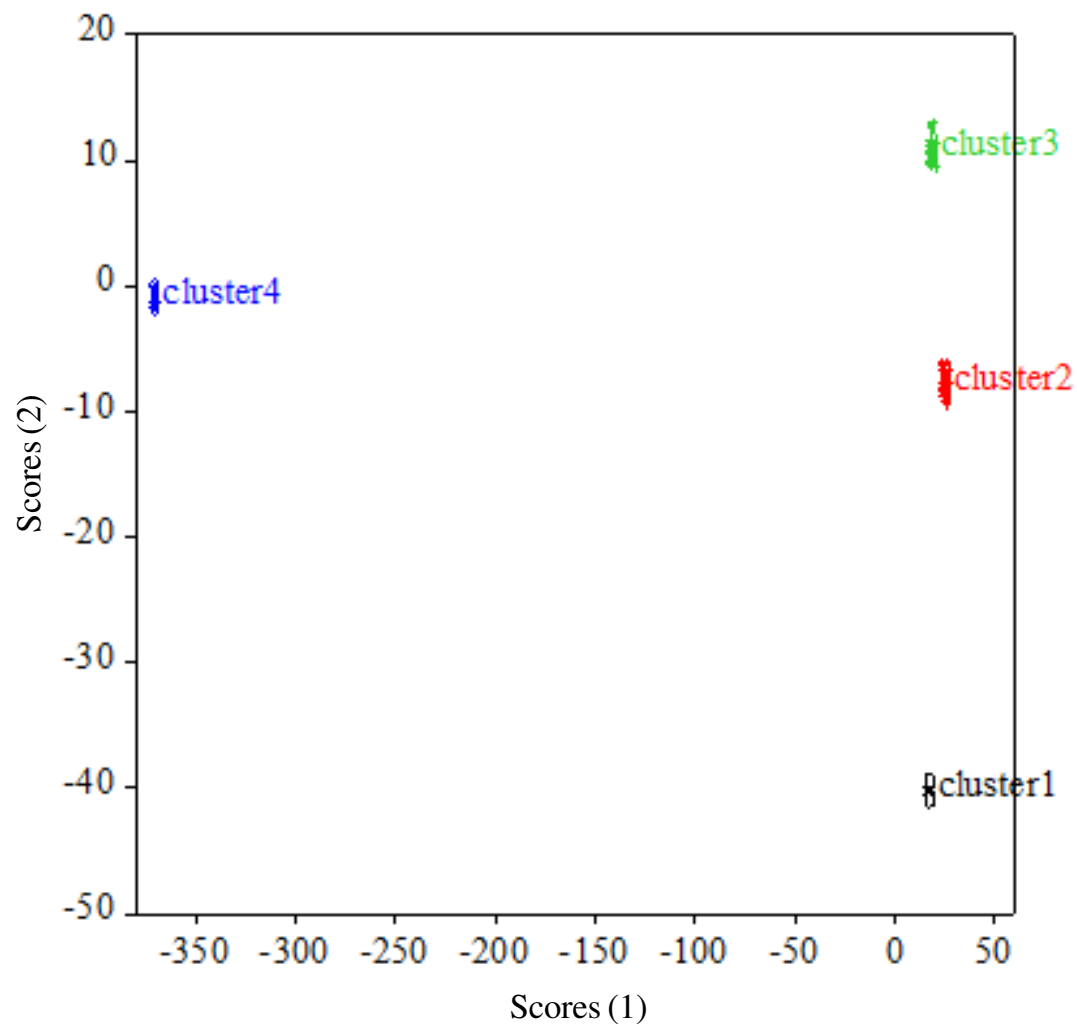

Figure 2. Biplot of first two discriminant functions showing cluster dissimilarities. 
TABLE 4. Mean squares of some of the variables and their significance in clustering of study accessions

\begin{tabular}{lllllllllllllll}
\hline Source & d.f & CLBL & CLBW & DG & FCD & FCL & FCP & FFW & FFY & FLW & FPI & FPL & FPP & FPT \\
\hline Experiment & 1 & 2515.8 & 539.1 & 1.008 & 113.2 & 4.123 & 4.453 & 345.37 & 168538.0 & 27319.4 & 45.72 & 19.97 & 30030.5 & 191.5 \\
Cluster & 3 & $418.8^{* * * *}$ & $86.6^{* * * *}$ & $102.5^{* * * *}$ & $3154.5^{* * *}$ & $2040.5^{* * * *}$ & $129.0^{* * *}$ & $3144.1 * * *$ & $1159353.0^{* * * *}$ & $272.3^{* * * *}$ & $32.0^{* * * *}$ & $39.3 * *$ & $17918.5^{* * *}$ & $50.0^{* * *}$ \\
Residual & 48 & 7.418 & 1.348 & 2.259 & 11.28 & 3.276 & 2.902 & 15.16 & 19902.0 & 24.11 & 0.809 & 6.471 & 321.2 & 3.862 \\
\hline
\end{tabular}

$*$, ** and *** stand for significance of cluster distinctiveness based on particular trait at a $=5,1$ and $0.1 \%$, respectively

$\mathrm{CLBL}^{\prime}$ cotyledonous leaf blade length, CLBW = cotyledonous leaf blade width, $\mathrm{DG}=$ days to germination, $\mathrm{FCD}=$ fruit cross section diameter, FCL $=$ fruit calyx length, FCP = fruit color at physiological ripeness, FFW = fruit fresh weight, FFY = fruit fresh yield, FLW = data to first flower appearance, FPI $=$ fruits per inflorescence, $\mathrm{FPL}=$ fruit pedicel length, $\mathrm{FPP}=$ fruits per plant, $\mathrm{FPT}=$ fruit pedicel thickness

TABLE 5. Discriminant scores for cluster means and inter-cluster distances

\begin{tabular}{|c|c|c|c|c|c|c|c|c|}
\hline \multicolumn{4}{|c|}{ Discriminant scores for cluster means } & \multicolumn{5}{|c|}{ Inter-cluster distances - Mahalanobis (D-squared) } \\
\hline & Scores $(1)$ & Scores (2) & Scores (3) & & Cluster 1 & Cluster 2 & Cluster 3 & Cluster 4 \\
\hline Cluster 1 & 17.35 & -40.17 & -11.31 & Cluster 1 & 0 & & & \\
\hline Cluster 2 & 25.42 & -7.8 & 4.16 & Cluster 2 & 1352 & 0 & & \\
\hline Cluster 3 & 18.58 & 10.92 & -2.2 & Cluster 3 & 2694 & 438 & 0 & \\
\hline Cluster 4 & -370.95 & -0.88 & 0.57 & Cluster 4 & 152466 & 157172 & 151879 & 0 \\
\hline
\end{tabular}




\section{DISCUSSION}

Hierarchical clustering. The results on hierarchical clustering indicated existence of strong population structures within the $S$. aethiopicum 'Shum' group, contrary to observations made by Adeniji et al. (2012, 2013) and Plazas et al. (2014). However, it is notable that the duo did not assess the structure based on Mantel test, which gives a cophenetic correlation coefficient (CPCC), and they compared all the four recognised morphotypes of S. aethiopicum (Shum, Gilo, Kumba and Aculeatum) in 'one' analysis (Adeniji et al., 2012, 2013; Plazas et al., 2014; Gramazio et al., 2016). The CPCC is one of the reliable measures of genetic diversity applicable to both molecular and morpho-agronomic data variables (Murtagh, 2017; Nikoliæ et al., 2017). The higher the CPCC (closer to 1.0) at high confidence level, is the stronger the distinctiveness of observed dendrogram clusters and reliability of hierarchical clustering (Nikoliæ et al., 2017). After clustering, it was imperative to carryout MANOVA to eliminate data redundancy, which could have occurred as a result of introducing 'cluster' as a predictor variable for the response of different traits measured. After MANOVA, linear discriminant analysis (LDA) considers 'cluster' as a dependent (response) variable as predicted by measured traits (Arandas et al., 2017).

Discriminant analysis of clusters. From LDA results, very high canonical correlation coefficients indicate that all three discriminant functions (DFs) generated were generally very important in dissecting variatal contribution to distinct clusters; in agreement with guidelines by Harding and Payne (2012) and Jombart and Collins (2015). According to Harding and Payne (2012), and Jombart and Collins (2015), the higher the correlation coefficients, the more clear-cut are the differences among clusters (Jombart and Collins, 2015). Specifically, the order of importance of the DFs in distinguishing among clusters was such that:
DF 1 was slightly superior to DF 2, and the DF 2 is slightly superior to DF 3.

The biplot of DF 2 scores and DF 1 scores showed a visual display of four distinct clusters. The distinctness of clusters was supported by generally high values of both inter-cluster distances and discriminant scores for cluster means. Members of cluster4 (accessions 160 and 145) possessed uniquely higher mean values for petiole length (PEL), sepal length (SEL) or seed color (SEC), fruit calyx length (FCL) and seeds per fruit (SPF) than the rest of accessions. The SEL and SEC were moderate-strongly correlated. Specifically, accessions 160 and 145 had orange-yellow fruits. Further, the biplot showed that DF 1 largely served to separate cluster4 from the rest of clusters. The observation suggests that other than leaf area, reproductive traits are putatively good morphological markers in S. aethiopicum 'Shum' group. Similar views were made by Adeniji et al. (2012) and Plazas et al. (2014) when they studied world collections of $S$. aethiopicum groups namely Shum, Gilo, Kumba and Aculeatum for genetic diversity based on morphological attributes.

Judging from highest discriminant score for Cluster 1 mean under DF 2, supported by correlations between data variates and DF 2, it implies that Cluster 1 (only one member, accession 185P, represented this cluster) was considered unique. This was due to extremely high fruit fresh yield per plant (FFY), the least leaf fresh weight (LFW) and relatively high number of fruits per plant. The FFY and LFW were the most important predictors of cluster distinctiveness in DF 2; the traits had the highest scores from the correlation between all data variates and the DF 2. Reduced leaf size and high reproductive efficiency are known adaptive traits for survival under harsh environments (Fita et al., 2015; Basu et al., 2016; Mwale et al., 2017).

Cluster 1 members showed the highest departure from Cluster 2 and Cluster 3 (basing on discriminant scores for cluster means and inter-cluster distances) under DF 2. This 
implies that accession 185P is different from Cluster 2 and Cluster 3 members for LFW and FFY. Although Cluster 2 and Cluster 3 had the shortest inter-cluster distance, their discriminant scores for cluster means were most extreme under DF 2. Thus, the traits that made Cluster 1 unique are also important in discriminating between Cluster 2 and Cluster 3.

The third discriminant function (DF 3) and DF 2 were important in separating cluster 1 from Cluster 2 where LFY (or LPP; these are strongly correlated), FFY, VSV, FPP, HID (or HIF; HID and HIF are correlated traits), and PGH are responsible traits (Fig. 2). Contrary to Adeniji et al. (2012) and Plazas et al. (2014) whose findings emphasized reproductive traits as major drivers of variability in $S$. aethiopicum, results from this study indicated equal importance of both vegetative and reproductive traits in distinguishing among the Shum accessions. Additionally, the visual seedling vigor offers opportunity for earlystage discrimination among Shum germplasm.

\section{CONCLUSION}

There is significant genetic diversity within $S$. aethiopicum Shum, which can support breeding interventions to develop improved varieties, as a way of addressing the crop's productivity constraints. Thirteen canonical variates, which best explained the structure by way of high loadings in each discriminant function, are potential morphological markers in the Shum. The canonical variates include seedling vigour for early-stage separation among accessions or individuals of a breeding population. At vegetative (harvest maturity of 8 weeks after planting); petiole length, leaf fresh weight, number of leaves per plant, harvest fresh index, harvest dry index and plant growth habit are the major discriminating variables. Varieties with favorable scores of the said traits (harvest index and leaf fresh weight, in particular) at vegetative stage are of direct importance to consumers and farmers. To breeders and seed companies, the possession of reproductive fitness traits is key to sustainability. As such; sepal length, seed color, fruit calyx length, number of seeds per fruit, fruit fresh yield and number of fruits per plant which were among the best predictors of diversity; offer opportunities for improving crop productivity through cross-breeding research and seed supply to farmers.

\section{ACKNOWLEDGEMENT}

This work was supported by WACCI/German Academic Exchange Programme, Makerere University/EU-Intra-ACP mobility project and Forum for Agricultural Research in Africa (FARA/PAEPARD-CRFII). We are also grateful to Ms. Julian Mildred Nakanwagi for assistance in routine screen house activities and data entry, Ms. Nahamya Pamela Kabod for providing the germplam and Dr. Michael Masanza for allowing the use of facilities at the Faculty of Science and Technology (UCU) during the study.

\section{REFERENCES}

Abukutsa-Onyango, M. 2014. Strategic repositioning African indigenous vegetables and fruits with nutrition, economic and climate change resilience potential. In: Novel Plant Bioresources. Gurib-Fakim, A. (Eds.). London: John Wiley and Sons. pp. 361-369.

Adeniji, O.T., Kusolwa, P.M. and Reuben, S.O.W.M. 2012. Genetic diversity among accessions of Solanum aethiopicum L. groups based on morpho-agronomic traits. Plant Genetic Resources 10(03):177-185. https://doi.org/10.1017/S14792621 12000226

Adeniji, O.T., Kusolwa, P. and Reuben, S. 2013. Morphological descriptors and micro satellite diversity among scarlet eggplant groups. African Crop Science Journal 21(1):37-49. 
Alberti, M., Correa, C., Marzluff, J.M., Hendry, A.P., Palkovacs, E.P., Gotanda, K.M. and Zhou, Y. 2017. Global urban signatures of phenotypic change in animal and plant populations. Proceedings of the National Academy of Sciences 201606034. Arandas, J.K.G., da Silva, N.M.V., Nascimento, R. de B., Pimenta Filho, E.C. Albuquerque Brasil, L.H. de and Ribeiro, M.N. 2017. Multivariate analysis as a tool for phenotypic characterization of an endangered breed. Journal of Applied Animal Research 45(1):152-158. https:// doi.org/10.1080/09712119.2015.1125353

Asher, J., Williams, I.D. and Harvey, E.S. 2017. Mesophotic depth gradients impact reef fish assemblage composition and functional group partitioning in the main Hawaiian Islands. Frontiers in Marine Science 4. https://doi.org/10.3389/ fmars.2017.00098

Bajwa, S., Rupe, J. and Mason, J. 2017. Soybean disease monitoring with leaf reflectance. Remote Sensing 127(9):1-14. https://doi.org/10.3390/rs9020127.

Basu, S., Ramegowda, V., Kumar, A. and Pereira, J.G. 2016. Plant adaptation to drought stress. F1000Research 5:1554. h t t p s : / / d o i.org/10.12688/ f1000research.7678.1

Bisamaza, M. and Banadda, N. 2017. Solar drying and sun drying as processing techniques to enhance the availability of selected African indigenous vegetables, Solanum aethiopicum and Amaranthus lividus for nutrition and food security in Uganda. African Journal of Food Science and Technology 8(1):001-006.

Cernansky, R. 2015. Super vegetables Nature 522(7555): 146 .

Fita, A., Rodríguez-Burruezo, A., Boscaiu, M., Prohens, J. and Vicente, O. 2015. Breeding and domesticating crops adapted to drought and salinity: A new paradigm for increasing food production. Frontiers in Plant Science 6. https://doi.org/10.3389/fpls.2015.00978
Gramazio, P., Blanca, J., Ziarsolo, P., Herraiz, F. J., Plazas, M., Prohens, J. and Vilanova, S. 2016. Transcriptome analysis and molecular marker discovery in Solanum incanum and $S$. aethiopicum, two close relatives of the common eggplant (Solanum melongena) with interest for breeding. BMC Genomics 17(1). https://doi.org/ 10.1186/s12864-016-2631-4

Harding, S. and Payne, R. 2012. A guide to multivariate analysis in GenStat $\left(15^{\text {th }}\right.$ Edition). 5 The Waterhouse, Waterhouse Street, Hemel Hempstead, Hertfordshire HP1 1ES, UK: VSN International.

Herklotz, V., Mieder, N. and Ritz, C.M. 2017. Cytological, genetic and morphological variation in mixed stands of dogroses (Rosa section Caninae; Rosaceae) in Germany with a focus on the hybridogenic $R$. micrantha. Botanical Journal of the Linnean Society 184(2):254-271.

Jombart, T. and Collins, C. 2015. A tutorial for discriminant analysis of principal components (DAPC) using adegenet 2.0. 0. Imperial College London-MRC Cent Outbreak Anal Model 43. Retrieved from http://adegenet.r-forge.r-project.org/files/ tutorial-dapc.pdf

Kiełbowicz-Matuk, A., Rey, P. and Rorat, P. 2014. Interplay between circadian rhythm, time of the day and osmotic stress constraints in the regulation of the expression of a Solanum Double B-box gene. Annals of Botany 113:831-842. https://doi.org/doi:10.1093/aob/mct303

Kouassi, A., Béli-Sika, E., Tian-Bi, T., AllaN'Nan, O., Kouassi, A., N'Zi, J.C. and TioTouré, B. 2014. Identification of Three Distinct Eggplant Subgroups within the Solanum aethiopicum Gilo Group from Côte d'Ivoire by Morpho-Agronomic Characterization. Agriculture 4(4):260-273. https://doi.org/10.3390/agriculture 4040260

Kubie, L.D. 2013. Evaluation of genetic diversity in garden egg (Solanum 
aethiopicum) germplasm in Ghana. MSc Thesis, University of Ghana, Ghana. 108pp. http://197.255.68.203/handle/ $123456789 / 5825$

Murtagh, F. 2017. Massive data clustering in moderate dimensions from the dual spaces of observation and attribute data clouds. arXiv Preprint arXiv:1704.01871. Retrieved from https://arxiv.org/abs/ 1704.01871

Mwale, S.E., Ssemakula, M.O., Sadik, K., Alladassi, B., Rubaihayo, P., Gibson, P. and Edema, R. 2017. Estimates of combining ability and heritability in cowpea genotypes under drought stress and non-stress conditions in Uganda. Journal of Plant Breeding and Crop Science 9(2):10-18.

Nikoliæ, A., Kostadinoviæ, M., Vanèetoviæ, J. Stankoviæ, G. and Ignjatoviæ-Miciæ, D. 2017. Comparison of statistical methods for genetic similarity evaluation of maize inbred lines. Field \& Vegetable Crops Research/Ratarstvo I Povrtarstvo 54(1).

Pincus, L.M. 2015. Increasing indigenous vegetable yield and nutritional quality through traditionally-and scientificallyinformed soil fertility management. PhD Thesis, University of California, USA. 139pp. Davis, ProQuest Dissertations Publishing 3723701. https://search. proquest.com/openview/a86362ceffc 188b0e0f5260629ea52ee/1?pq-origsite= gscholar \&cbl=18750 \&diss=y
Plazas, M., Andujar, I., Vilanova, S., Gramazio, P., Herraiz, F.J. and Prohens, J. 2014. Conventional and phenomics characterization provides insight into the diversity and relationships of hypervariable scarlet (Solanum aethiopicum L.) and gboma ( $S$. macrocarpon L.) eggplant complexes. Frontiers in Plant Science 5:1-13. https:// doi.org/10.3389/fpls.2014.00318

Saraçli, S., Doðan, N. and Doðan, Ý. 2013. Comparison of hierarchical cluster analysis methods by cophenetic correlation. Journal of Inequalities and Applications 203(1):1-8. doi:10.1186/1029-242X-2013203

Silva, A.R. and Dias, C.T.S. 2013. A cophenetic correlation coefficient for Tocher's method. Pesquisa Agropecu?ria Brasileira 48(6):589-596. https://doi.org/10.1590/ S0100-204X2013000600003

Von Grebmer, K., Bernstein, J., de Waal, A., Prasai, N., Yin, S. and Yohannes, Y. 2015. 2015 Global hunger index: Armed conflict and the challenge of hunger. Bonn, Germany; Washington, D.C. and Dublin, Ireland: Welthungerhilfe. International Food Policy Research Institute (IFPRI) and Concern Worldwide. http://dx.doi.org/ 10.2499/9780896299641

World Vegetable Center. 2017. Annual Report 2016 (No. Publication 17-814) Shanhua, Taiwan: World Vegetable Center. p. 67. 